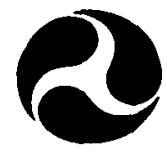

U.S. Department of Transportation

National Highway

Traffic Safety

Administration

\title{
Summary Report: Field Test of Combined Speed, Alcohol, and Safety Belt Enforcement Strategies
}


This publication is distributed by the U.S. Department of Transportation, National Highway Traffic Safety Administration, in the interest of information exchange. The opinions, findings and conclusions expressed in this publication are those of the author(s) and not necessarily those of the Department of Transportation or the National Highway Traffic Safety Administration. The United States Government assumes no liability for its contents or use thereof. If trade or manufacturers' name or products are mentioned, it is because they are considered essential to the object of the publication and should not be construed as an endorsement. The United States Government does not endorse products or manufacturers. 


\begin{tabular}{|l|l|l|}
\hline 1. Report No. & R. Recipient's Cotolog No. \\
DOT HS 808242 & 2. Government Accession No, & Seport Date \\
\hline 4. Title and Subtitle Summary Report: Field Test of \\
Combined Speed, Alcohol, and Safety Belt Enforcement \\
Strategies
\end{tabular}

15. Supplementary Notes

Ted Anderson served as COTR on the project.

16. Abstroct

This report summarizes the implementation of traffic safety programs in three communities: Knoxville, Terınessee; Wichita, Kansas; and Lexington, Kentucky. The goal of each program was to reduce the incidence of speeding, alcohol-impaired driving (DWI) and non-use of safety belts through well-publicized enforcement strategies focusing attention on all three areas. The programs sequentially emphasized five different combined enforcement strategies over a period of approximately one year. A public information and education program that focused on each strategy ran for about two months. The overall results of this project provide some support to the basic premise of combined enforcement, but raise some questions about the practicality of operating such a program over an extended period of time. To be effective, it appears that combined enforcement programs should incorporate increased intensity of enforcement of the target laws as well as a strong public information and education program supporting the effort. Only one. of three sites was able to sustain increased enforcement in all three areas, and had the most positive results. Details of the programs and evaluation results for each of the sites appear in separate reports.

17. Key Words

Speeding, DWI, safety belts, enforcement, evaluation
18. Distribution Statement

This document i.s available to the U.S. public through the National Technical Information Service, Springfield, VA 22161

19. Security Classif. (of this report)

20. Security Classif. (of this page)

21. No. of Poges

22. Price 


\section{ACKNOWLEDGEMENTS}

The authors are grateful to the many individuals who helped with this project. Persons and agencies that were especially helpful in the various states that participated are acknówledged below.

\section{TENNESSEE}

The actual execution of the Knoxville program was performed entirely by the Knoxville Police Department (KPD). We are grateful to Chief Phil Keith of the Department for his enthusiastic support of the combined enforcement experiment and for assigning key members of his staff to work on the project. Ms. Janet Brewer, the Traffic Safety Coordinator for the Department, coordinated the KPD effort. Without her outstanding effort, this project would not have been possible. We are also grateful to numerous others in the KPD, including Judith Martin of the Planning Department and Lieutenant Robert Coker. Ms. Martin was especially helpful in initiating the project and in arranging for data collection, and Lieutenant Coker played a key role in the enforcement effort. We are most grateful to those in the local media who contributed their time and resources in support of the public information component of the project. The effort of Knoxville television station WBIR-TV in producing and running public service announcements about the project is especially appreciated.

Chattanooga was the comparison site for the Knoxville program and the Lexington program. Its role was to provide data on related traffic enforcement activity in Chattanooga. Ms. Peggy Ramage of the Hamilton County Department of Health was our principal point of contact in Chattanooga. The Department kindly provided us the results of their survey of attitudes and driving behavior of Chattanooga drivers.

The Tennessee Department of Safety also played a critical role in the data collection effort associated with this project. The Knoxville and Chattanooga surveys of driver attitudes and driving behavior were conducted in the Department's driver license stations. Mr. Dean Tyler of the Department of Safety arranged the preparation of traffic accident tapes for Knoxville and Chattanooga for our use in our evaluation of the project.

\section{KANSAS}

We would like to offer a special thanks to Rosalie Thornburgh, the Kansas Traffic Safety Administrator, for her assistance and guidance throughout the Wichita program.

The execution of the Wichita program was performed by the Wichita Police Department (WPD). We are grateful to Chief Rick Stone and Deputy Chief Steve 
Trainer for promoting the implementation of the program in Wichita and Major $\mathrm{K}$. Tyler Brewer for his direction and support of the Traffic Trifecta project. We would especially like to thank Lieutenant Ronald R. Harris for coordinating the WPD effort both within the department and in the community. Through his efforts local resources were obtained to support the project. We are most grateful to those in the local media who contributed their time and resources in support of the public information component of the project. The efforts of Donrey Advertising in designing the project logo and in donating billboards was greatly appreciated, as well as the efforts of television stations KSNW and KWCH for taping and airing the PSAs.

Topeka was the comparison site for the Wichita project. We would like to thank Captain Dean Forrester and Missy Cowhick of the Topeka Police Department for providing information and data relating to Topeka and Shawnee County.

We would especially like to recognize those in state and local government agencies in Kansas who assisted us. Jim Schaller, Research Analyst with the Office of Traffic Safety, provided accident data tapes. The surveys of driver attitudes and behavior were conducted in the Drivers Licensing Offices in Wichita and Topeka. We would like to thank John Smith, Administrator of Driver Control, and Sondra Dexter, Chief-Driver License Examining, for their support of our survey efforts with special thanks to Hazel Balthazor of the Topeka Licensing Office for overseeing the collection efforts in Topeka.

\section{KENTUCKY}

The actual execution of the test program was performed entirely by the Lexington-Fayette, Kentucky Police Department (LPD). We are grateful to Assistant Chief Larry Ball of the Department for his enthusiastic support of the combined enforcement experiment and for assigning key members of his staff to work on the project. We are most grateful to those in the local media who contributed their time and resources in support of the public information component of the project. The effort of Lexington television station WXXX-TV in producing and running public service announcements about the project is especially appreciated.

The Kentucky Department of Safety (KDS) also played a critical role in the data collection effort associated with this project. The surveys of driver attitudes and behavior were conducted in the Department's driver license stations in Lexington. The Department also provided traffic accident tapes for use in our evaluation of the project.

\section{PROJECT}

Mid-America was assisted in this project by two subcontractors, the University of North Carolina Highway Safety Research Center (HSRC) and the Center of Applied Research (CAR). We extend our thanks to our colleagues at Mid-America, HSRC, and CAR who helped in this study. Peter V. Murphy of Mid-America assisted in the PI\&E effort, and Georgine Russell of Mid-America assisted in producing the 
report. Richard Knoblauch and Marsha Nitzberg of CAR played key roles in collecting field data of vehicle speeds and seatbelt use in all of the sites.

We thank all who assisted. 


\section{TABLE OF CONTENTS}

ACKNOWLEDGEMENTS $\ldots \ldots \ldots \ldots \ldots \ldots \ldots \ldots$ iii

TABLE OF CONTENTS $\ldots \ldots \ldots \ldots \ldots \ldots \ldots \ldots$ vii

EXECUTIVE SUMMARY $\ldots \ldots \ldots \ldots \ldots \ldots \ldots \ldots \ldots$ ix

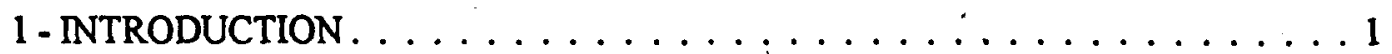
GENERAL NATURE OF THE PROJECT $\ldots \ldots \ldots \ldots \ldots \ldots$

PROJECT SCOPE AND APPROACH $\ldots \ldots \ldots \ldots \ldots \ldots \ldots$

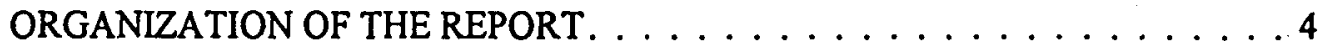

2 - SITE SELECTION CRITERIA $\ldots \ldots \ldots \ldots \ldots \ldots \ldots$

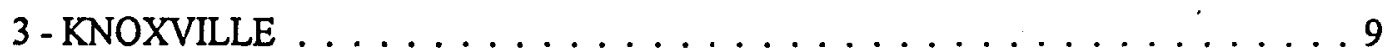

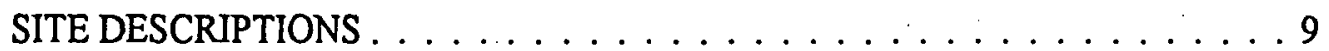

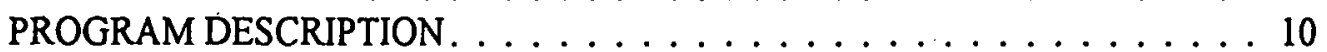

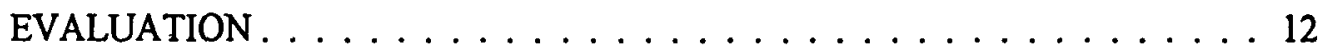

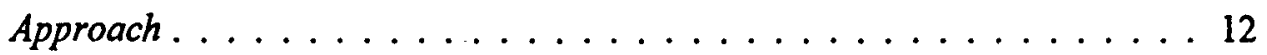

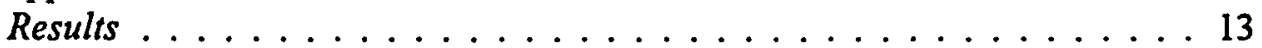

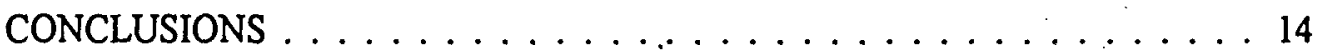

4 - WICHITA . . . . . . . . . . . . . . . . 15.

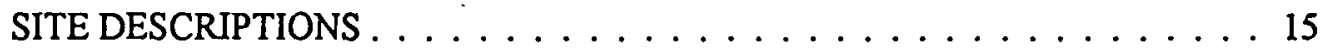

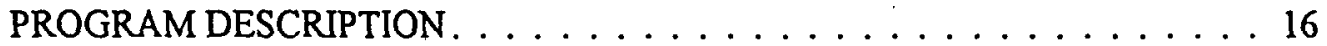

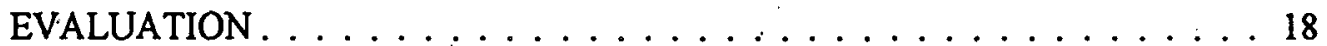

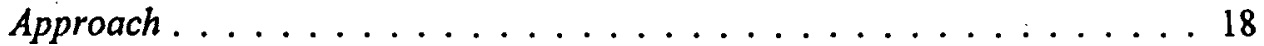

Results . . . . . . . . . . . . . . . . . . . . 19

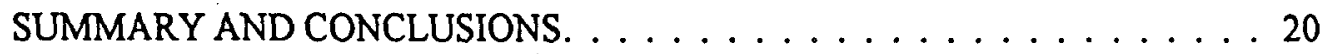

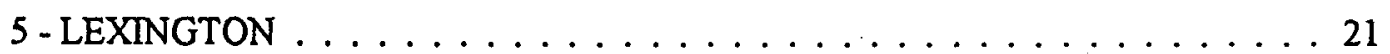

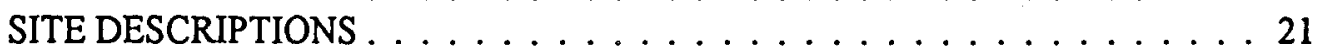

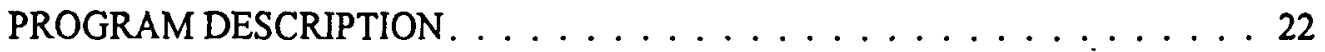

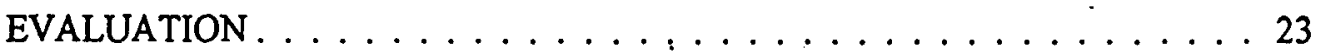

Approach. . . . . . . . . . . . . . . 23

Results ...................... 24

SUMMARY AND CONCLUSIONS. . . . . . . . . . . 25

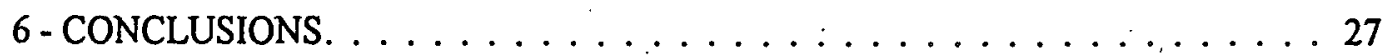




\section{EXECUTIVE SUMMARY}

This report summarizes the implementation and evaluation of a project in three sites to test the hypothesis that combined speed, alcohol, and seatbelt enforcement strategies, coupled with a strong public information and education program (PI\&E), can reduce the incidence of speeding, alcohol-impaired driving, and non-use of seatbelts. The three sites were Knoxville, Tennessee; Wichita, Kansas; and Lexington, Kentucky. This project publicized the enforcement of several highway safety laws in combination, rather than enforcement of one particular law. This approach was designed to make enforcement more efficient in raising perceived risk of arrest for each type of violation and also to achieve increased deterrence by creating a perception of more severe penalties for multiple violations occurring in a single incident. We hypothesized that, as a result, deterrence for one category of violation may be enhanced by the perceived severity of sanctions for another.

Each program was designed to sequentially emphasize five different combined enforcement strategies during a period of approximately one year. A PI\&E campaign focusing on each strategy was to operate for about two months. A general program theme was established for all of these campaigns, stressing the concept of simultaneous enforcement of speeding, DWI, and occupant restraint laws. The themes selected by the three sites were:

Knoxville

Triple Jeopardy: Speeding, Drunk Driving and Belt Use - In Knoxville, if you're stopped for one, you're checked for all three.

\section{Wichita}

Traffic Trifecta: Buckle Up - Slow Down - Drive Sober. Don't gamble with a life!

\section{Lexington}

Traffic Watch.

The evaluation effort was directed at measuring the effect of the combined enforcement / PI\&E program on:

- driver awareness of the program;

- driver perceptions of enforcement;

- driver self-reported behavior with respect to speeding, drinking-driving, and seatbelt use;

- measured speed distributions and seatbelt use at several locations throughout the program period; and

- accidents and accident variables related to drinking-driving, speeding and seatbelt use. 
A comparison site was used for each test site to help recognize trends that could affect the test site and confound the effects of the program in the test site. The comparison site was chosen so as to match the test site as closely as possible except that it planned no special traffic law enforcement program.

The first program began in September, 1990, and the last program continued through May, 1992.

This results of this project provide support for the premise that a combined enforcement program against DWI, speeding, and non-use of seatbelts can have a positive general deterrence impact when properly designed and executed, but raise some questions about the practicality of operating such a program over an extended period of time. To be effective, it appears that combined enforcement programs should incorporate increased intensity of enforcement of the target laws as well as a strong public information and education (PI\&E) program supporting the enforcement effort and its highway safety benefits.

In our project, the programs that had both of these elements for either DWI or speeding or both showed an effect for those behaviors (Table 1). Programs that did not have both elements for one or both of these two behaviors did not show an effect. Our project's results for the third target behavior, nonuse of seatbelts, were inconclusive in that one site (Wichita) with increased enforcement and PI\&E showed no effect, while another site (Lexington) with increased enforcement and PI\&E was able to maintain its already high seatbelt usage rate throughout its program period. We note, however, that all of the sites had secondary-enforcement laws for adult seatbelt violations. Possibly, the combined enforcement effort would have shown more positive results against seatbelt violations had the sites been able to practice primary enforcement. (Research has shown that the largest increases in seatbelt usage have occurred in jurisdictions having primary-enforcement laws and enforcing those laws.)

Of the two sites that showed clearly positive results in this project, one (Wichita) had an effect on DWI, and the other (Lexington) had an effect on DWI and speeding. Wichita experienced a reduction of at least $20 \%$ in proxies of alcohol-related crashes. Lexington had a reduction of alcohol-crash proxies in the $10 \%$ range and also a $12 \%$ reduction in the number of vehicles exceeding the speed limit by at least $5 \mathrm{mph}$. Further, Lexington also had a reduction in minor injury accidents of about $17 \%$, a possible reflection of these lower speeds.

One of the two comparison sites selected for this study (Chattanooga) decided to operate a speeding campaign during a portion of the period in which it was being used as a comparison site. The campaign was accompanied by an intensive PI\&E effort, but did not involve increased enforcement of DWI or nonuse of seatbelts. This campaign also achieved a positive general deterrence impact on speeding-related accidents: injury accidents in Chattanooga declined some $8 \%$ during its program. When compared to Lexington (which also had a successful effort against speeding), Chattanooga apparently had a greater effect on speeding-related accidents, since it showed a reduction in all injury accidents, not just minor injury accidents. However, 
this effect was achieved without the positive effect on DWI (and the possible positive effect on nonuse of seatbelts) that occurred in Lexington. Thus, there is some evidence to suggest that a combined enforcement program might have a greater overall highway safety impact than a single-violation program of comparable magnitude. However, this evidence is certainly not conclusive and needs to be supported by further research to verify.

With respect to the operation of a combined enforcement program, we found that such a program can place a strain on police resources because of the need to simultaneously increase enforcement intensity for all three of the target behaviors. In times of high demand for polices services and lack of adequate resources to meet that demand, it may be difficult for some departments to allocate sufficient additional resources to traffic-law enforcement.

It is possible that a more effective PI\&E program would help lessen the amount of additional enforcement intensity needed for a combined enforcement effort. For example, we noted in our discussion of the results of the Lexington program how a PI\&E program explicitly emphasizing the combined enforcement concept might be difficult for drivers to grasp. It could be that the PI\&E effort would be more productive if the individual targeted behaviors were emphasized sequentially in the PI\&E campaign, with the combined-enforcement message assuming a secondary role.

In sum, the results of this study are encouraging but inconclusive as to the traffic safety impact of combined enforcement of DWI, speeding, seatbelt usage laws. In two of the test sites it was not possible to consistently maintain increased enforcement activity and associated publicity for all three of the target behaviors. The one site that was able to maintain increased enforcement activity and a high level of publicity for all three behaviors produced positive results against DWI and speeding. This site did. not produce any increase in seatbelt usage, but was able to maintain its already high usage rate. Another site that was able maintain increased publicity and related publicity against just one of the target behaviors, DWI, showed positive results for that target behavior, but for none of the others. The study also indicated that the single-emphasis approach employing increased enforcement and PI\&E also can have an impact which may be greater for the targeted behavior than that of the combined approach. 


\section{1 - INTRODUCTION}

\section{GENERAL NATURE OF THE PROJECT}

This report summarizes the implementation and evaluation of three programs to determine whether combined speed, alcohol, and seatbelt enforcement strategies, coupled with a strong public information and education program (PI\&E), can reduce the incidence of speeding, alcohol-impaired driving, and non-use of seatbelts. The sites of the three programs were Knoxville and Knox County, Tennessee; Wichita and Sedgwick County, Kansas; and Lexington and Fayette County, Kentucky. The project was conducted for the National Highway Traffic Safety Administration under Contract Number DTNH22-89-C-07396 entitled "Field Test of Combined Speed, Alcohol, Safety Belt Enforcement Strategies."

This project publicized the enforcement of several highway safety laws in combination, rather than enforcement of one particular law. This approach was designed to make enforcement more efficient in raising perceived risk of arrest for each type of violation and also to achieve increased deterrence by creating a perception of more severe penalties for multiple violations occurring in a single incident. As a result, deterrence for one category of violation may be enhanced by the perceived severity of sanctions for another.

For example, a strategy may involve publicizing that all nighttime speeding stops will also include administration of a Preliminary Breath Test (PBT) for alcohol impairment (subject to probable cause constraints) and investigation of safety belt and child restraint use. Deterrence may be enhanced for the restraint and alcohol laws by an increased perception of the risk of arrest brought about by increased nighttime speeding enforcement. For the speeding violation, publicizing the enforcement itself may increase the perceived risk of arrest and also the perceived severity of punishment by the threat of a possible alcohol violation and its attendant sanctions.

This report is a summary and synthesis of the three reports that present the design and results of each program in detail. The reader is referred to these reports for additional detail.

\section{PROJECT SCOPE AND APPROACH}

Each of the three programs (Knoxville, Wichita, and Lexington) was based on a design concept requiring:

\footnotetext{
sites.

${ }^{1}$ In the remainder of this report, we use the names of the cities alone in referring to these three
} 
1. use of high-intensity; combined-enforcement strategies incorporating both new and traditional techniques; and

2. heavy use of public information and education tailored to match each of the enforcement strategies.

Two distinct types of effort were required in each of the programs, (1) design and implementation of the enforcement / PI\&E program, and (2) evaluation of that program. The design and implementation effort began with the selection of suitable jurisdictions in which to locate the programs. This involved contact with NHTSA's regional offices as well as drawing upon our own knowledge of traffic enforcement agencies throughout the country. Once a list of possible jurisdictions and agencies was developed, we set about contacting management staff in those agencies. Initially, the contacts were by telephone and through written correspondence. We then visited agencies that appeared promising to confirm their appropriateness. Criteria used in selecting sites are discussed later in this report and included those critical to enforcement and those critical to the PI\&E effort.

The evaluation effort was directed at measuring the effect of the enforcement $/$ PI\&E program on the following groups of variables:

- driver awareness of the program;

- driver perceptions of enforcement;

- driver self-reported behavior with respect to speeding, drinkingdriving, and seatbelt use;

- measured speed distributions and seatbelt use at several locations throughout the program period; and

- accidents and accident variables related to drinking-driving, speeding and seatbelt use.

At the lowest level, program activity was monitored. Two types of activity were generated by this program: enforcement and PI\&E. The activity evaluation tracked and assessed the enforcement and PI\&E effort over the course of the program. The enforcement data consist primarily of arrests for DWI and citations for speeding and non-use of restraints. The PI\&E data include such measures of exposure as the number of plays of PSAs by given stations, and number of special events held.

Higher levels of program evaluation dealt with the effects of the program activities on variables related to the target driving behaviors, that is, DWI, speeding, and seatbelt use. Awareness, perceived risk of enforcement, and self-reported behavior were measured through questionnaires filled out by drivers at driver license stations. The awareness component was concerned both with awareness of program messages as disseminated through PI\&E activities, and with the awareness of the enhanced enforcement activity generated by the program. Perceived enforcement risk dealt with the drivers' perception of the risk of getting arrested or ticketed for one of the three target violations, and self-reported behavior addressed the drivers' own reports of 
violating DWI, speeding, and seatbelt-use laws. The survey was conducted in each site pair before and after the program was initiated.

A field measurement program was conducted to obtain data on actual speeding and seatbelt-use behavior. Vehicle speeds were measured and seatbelt use was observed at several locations in the test and comparison sites. Several waves of measurements were conducted.

Finally, an analysis of traffic accidents was performed for both sites. The analysis was concerned with the time variation of accidents and accident losses involving DWI, speeding, and non-use of seatbelts.

The evaluation was designed to measure changes in these variables in the test site over the program period. In addition, a comparison site was sought to help recognize trends that could affect the test site and confound the effects of the program in the test site. The comparison site was chosen so as to match the test site as closely as possible, except that it planned no special traffic law enforcement program during the program period. This design would permit one to estimate the effectiveness of the combined enforcement effort relative to a nominal enforcement effort involving no special campaign of any kind.

Two comparison sites ultimately were chosen, Chattanooga and Hamilton County, Tennessee for Knoxville and Lexington; and Topeka and Shawnee County, Kansas for Wichita. As with the test sites, only the name of the city is used in this report when we refer to a comparison site.

In addition, we contacted highway safety practitioners and surveyed the literature to learn whether there had been any evaluations of single-strategy speed enforcement programs in jurisdictions similar to our test jurisdictions. If such data were available, it could be combined with the data from our pertinent site pairs to get an estimate of the benefit of a combined enforcement approach compared to a single-violation enforcement approach.

No literature was found reporting the jurisdiction-wide effects of such a campaign on speed distributions or traffic crashes. Prior research on speed-enforcement campaigns appears to have focused on their effects in the immediate vicinity of an enforcement symbol rather than within the entire jurisdiction served by an enforcement agency. However, a comparison site, Chattanooga, Tennessee, used in this project for the Knoxville, Tennessee test site did implement a single-strategy speed enforcement program in which the groups of variables listed above were quantified by our project team. The data (discussed later in this report) strongly suggest that the Chattanooga program was more effective against speeding and related crashes than was its prior nominal enforcement program, and that the program achieved its positive effects against speeding with no apparent negative effects on perceived enforcement or self-reported behavior with respect to DWI or seatbelt use. There were also no negative effects on observed use of seatbelts. 


\section{ORGANIZATION OF THE REPORT}

Criteria for selecting the various test and comparison sites are presented in Chapter 2. Chapters 3, 4, and 5 describe the programs in Knoxville, Wichita, and Lexington, respectively, and summarize the design and results of the evaluation in each of these sites. Chapter 6 presents the overall conclusions of the project. 


\section{2 - SITE SELECTION CRITERIA}

Our contract called for sites with populations between 200,000 and 500,000. Two categories of criteria were used in selecting sites of this size, those critical to enforcement and those critical to the PI\&E effort. Site selection criteria critical to enforcement included:

Willingness of police to cooperate. This criterion included the willingness to adhere to the experimental design (discussed later in this report), and the willingness to provide personnel and equipment needed for the enforcement efforts.

Conditions justifying speed enforcement. This criterion was aimed at ensuring that traffic laws, speed limits, and road conditions were such that a program that includes speed enforcement had a reasonable chance of influencing driver behavior.

Availability of data. This included specific data on the coincidence of problem behaviors (e.g., speeding and DWI) in the locality, for the purpose of planning the enforcement campaign. It also included the availability of more general data (accident, arrest, etc.) for determination of program effectiveness. It included the current availability (or reliable prospect of future availability) of independent attitudinal survey data on issues related to the project.

Quality and accessibility of accident data. Computer tapes from a central agency were preferable to hard copy from the local agencies, which would have to be retrieved and keypunched. The detail of information on the accident reports was also important; for example, data which contained the TAD scale for vehicle damage were deemed preferable to those which did not. Also, sites with more extensive police investigation of accidents were preferable to those which relied more heavily on operator reports.

Legal environment. Considerations were the requirements for a speeding citation, the definitions of the various levels of alcohol offenses, the legal techniques for determining $\mathrm{BAC}$, whether roadblocks were permitted, the exact requirements for safety belt use, and the strategies permitted for enforcing safety belt use. It was also important that there would be no new local or state legislation which would affect the legal basis for the enforcement strategies (è.g., repeal of a seatbelt law, or drastic strengthening of the drunk driving laws).

Availability of Comparison Sites. Desirable characteristics of comparison sites were: 
- Similarity in general social and economic characteristics.

- Similarity in general characteristics of the Highway Transportation System.

- Similarity in intensity of enforcement of target traffic law violations.

- Similarity in historic traffic law enforcement patterns and trends.

- No plans for changes in current traffic law enforcement and PI\&E practices.

- Similarity in historic accident patterns and trends.

- Data availability comparable to those of the test sites.

- Willingness to permit collection of speed and seatbelt use data.

Site Selection Criteria Critical to the PI\&E Campaign were:

Willingness of local police agencies to make true commitment to the program. This included the willingness on the part of the chief(s) to give the project high priority, to make resources available to make this a real and permanent initiative, and to take an active role in both the enforcement and public information activities.

Availability of an effective police-based local coordinator. The potential for success for this type of public information program can rest largely on the effectiveness of the local coordinator. The ability to work well with the public, the media, and the departments cooperating in the program was essential. A person based within the enforcement agency was desired.

Ability to develop widespread local ownership and resources. This project had few funds available for materials and promotions because the development of a program that could be operated locally without federal funding was desired. It was therefore necessary to choose a site that had sufficient resources available to supplement the efforts of the law enforcement agencies. These resources included support of local businesses, industry and volunteer and civic groups.

Availability of local media. Local television and radio stations, newspapers and other media outlets were necessary to get the messages out to a significant portion of the driving public. Ideally, the site would be its own media market or the main metropolitan area within the market. The support of the media in donating public service efforts to the program, including the development, production and play of public service announcements, was an essential ingredient.

The suitability of Knoxville, Wichita, and Lexington as test sites and of Chattanooga, Tennessee, and Topeka as comparison sites with respect to these criteria was assessed and documented in interim reports to NHTSA. Site pairs recommended to and accepted by NHTSA were (See. Figure 1 below): 
- Knoxville and Chattanooga;

- Wichita and Topeka; and

- Lexington and Chattanooga.

Figure 1: Location of Study Sites

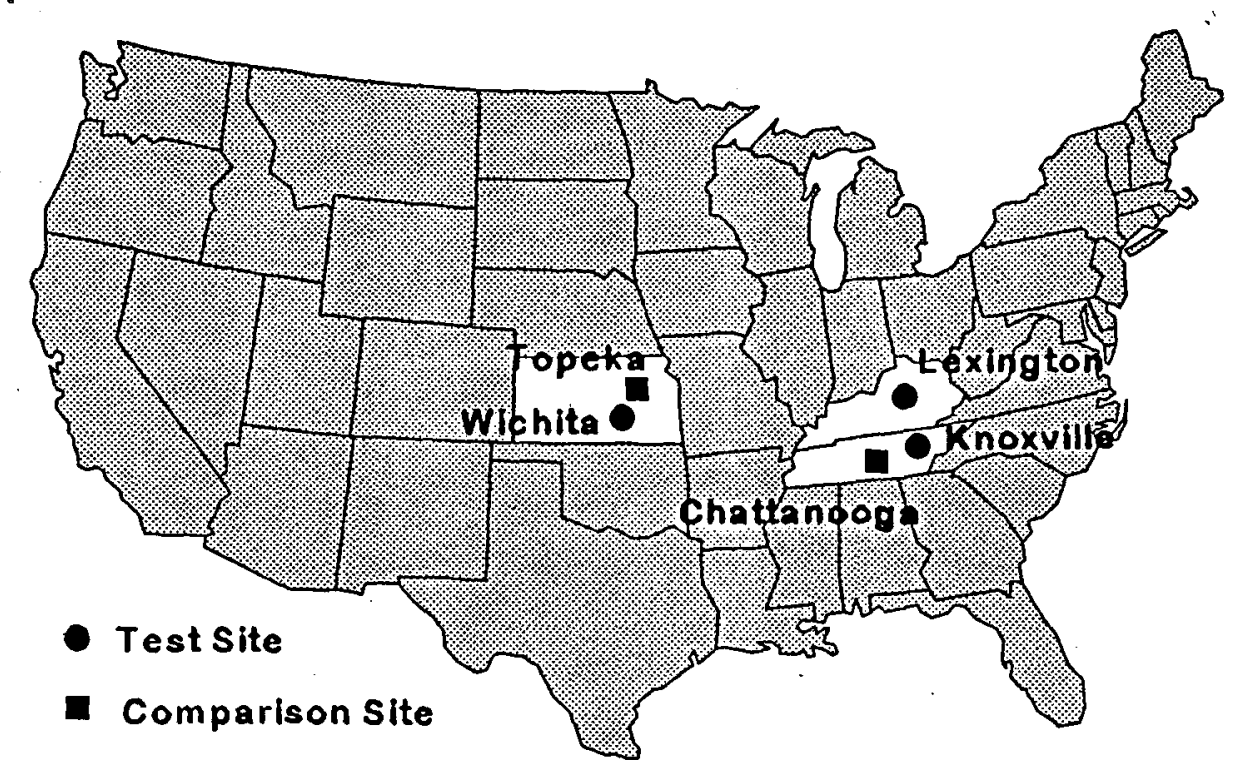

All programs were operated as a local project housed within the local police department. The development and operation of enforcement and PI\&E strategies was also a local effort. Mid-America's role was to provide assistance as required in the design of the programs and in the development of PI\&E materials. The University of North Carolina Highway Safety Research Center participated as a subcontractor to Mid-America with responsibility for assisting in the PI\&E effort. Significant local effort was put forth in all sites in coordinating the project and in producing PI\&E materials. 


\section{3 - KNOXVILLE.}

\section{SITE DESCRIPTIONS}

Knoxville is located in eastern Tennessee in Knox County. The city has a population of about 165,000 , compared to about 336,000 in the county. The county (excluding the city) is largely rural. About $35 \%$ of the population in the county are under 25 years of age, and about $13 \%$

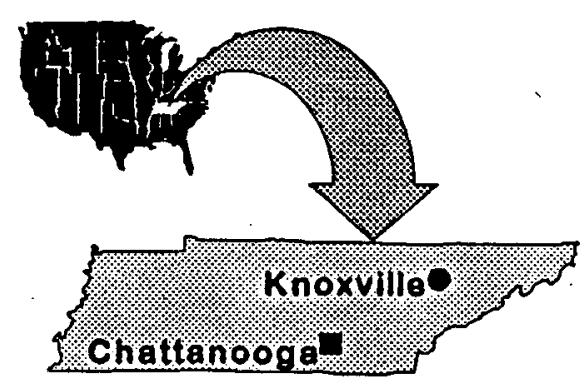
are 65 or older. Some $10 \%$ are classified as minority (primarily AfricanAmerican).

Per capita personal income for the county is about $\$ 17,000$, about the same as the state as a whole. About $11 \%$ of Knox County families were below the poverty level in income in 1979 , a bit less than the state as a whole $(13 \%)$. The unemployment rate

in the county was $4.0 \%$ in 1990 , also less than that of the state as a whole which had a rate of about $5.2 \%$.

Law enforcement in Knox County is performed almost entirely by the Knoxville Police Department and the Knox County Sheriffs Department. The Sheriff is more than a jailer, and does considerable patrol outside of the city and some patrol on interstate highways within the city. These two agencies collaborate from time to time, including establishing and operating sobriety checkpoints. The Tennessee Highway Patrol does very little law enforcement in Knox County, and there are no other smaller police departments of any significance to this project.

The KPD has been active in traffic law enforcement. The most directly related enforcement program was a three-year $55 \mathrm{mph}$ speed enforcement program. However, this program was not widely publicized and was not integrated with other traffic law enforcement efforts.

The comparison site for Knoxville was Chattanooga, Tennessee and is located in Hamilton County in the mountainous, southeastern part of Tennessee, immediately north of the Georgia border. The city has a population of about 250,000 , and the county has a population of about 300,000. As is the case in Knoxville and Knox County, the county (excluding the city) is largely rural. About $28 \%$ of the population are under 18 years of age, and about $11 \%$ are over 65 . About $30 \%$ are classified as minority (primarily African-American).

Per capita income for the county is about $\$ 12,000$, The unemployment rate in the county was $7.7 \%$ in 1984 .

In Chattanooga the Chattanooga Police Department and the Hamilton County Sheriff's Department are the primary traffic law enforcement agencies. Some 
enforcement is performed by the Tennessee Highway Patrol. The CPD has 354 sworn officers, 15 of whom are assigned to the Traffic Division. Chattanooga has a DUI Task Force, which was established in 1984 as a part of a comprehensive, community based drunk-driving program. The Task Force consists of five law enforcement officers whose duties include only drunk driving enforcement.

Both jurisdictions enforce seatbelt usage under a secondary-enforcement law which requires a stop for some other violation before a warning or citation may be issued.

The two sites were compared on a number of parameters and were found to be similar. These parameters included: applicable laws and ordinances, primary enforcement agency, size of geographical area, population, per capita income, unemployment, number of registered vehicles, miles of various types of roadways, historic accident patterns and trends, intensity of traffic enforcement, number of speeding citations, number of DWI arrests, historic enforcement patterns and trends, total calls for police services, and data availability.

\section{PROGRAM DESCRIPTION}

The Knoxville Triple Jeopardy program sequentially emphasized five different combined enforcement strategies during a period of approximately one year, beginning in September, 1990. A PI\&E campaign focusing on each strategy was operated for about two months. The first campaign was preceded by a one-month period of planning and collection of baseline data, and the last campaign was followed by a one-month period of post-operations data collection. A general program theme underlaid all of these campaigns, stressing the concept of simultaneous enforcement of speeding, DWI, and occupant restraint laws. The theme selected by the Knoxville Police Department was:

Triple Jeopardy: Speeding, Drunk Driving and Belt Use - In Knoxville, if. you're stopped for one, you're checked for all three.

The logo used the image of a key chain imprinted with the words speeding, drunk driving, and belt use. The image for the Triple Jeopardy concept was a composite high-contrast photograph of three police cars. The police cars were used interchangeably with the image of three motorcycle officers. The message was that each stop is actually three enforcement stops in one. To give the program continuity and high recognition, these images were used on all materials and public service announcements produced. A brochure explained the program and highlighted the various strategies. In each strategy, citations were given or arrests were made as appropriate. If a stop was made for speeding or DWI, officers observed for the other violation and for seatbelt usage during the stop:

The lead enforcement strategies of the five campaigns were: 
1. Sobriety Checkpoints. Checkpoints at key locations in Knox County using radar upstream to enhance the DWI "hit ratio" and to increase the perception of combined DWI-speeding enforcement. The Knox County Sheriffs department supported the Knoxville Police Department in this effort. Hard news coverage was received from the local television and radio stations and the Knoxville Journal.

- 2. Saturation Patrols. Patrol units were deployed about every two blocks in a given sector and were rotated to other sectors on a weekly basis, so that the entire Knoxville area was covered. Each patrol vehicle was equipped with hand-held radar, and the officers were trained in the use of visual cues for detecting alcohol-impaired drivers.

3. Interstate Speed Enforcement and Child Safety Device Enforcement. This was a two-part campaign emphasizing speed enforcement at designated sites on the interstate highways passing through Knoxville and enforcing the child passenger law which permits primary enforcement of non-use of restraints for children under four years old. The first component of this campaign used various tactics for detecting speeding violations on interstate highways, including pacing during which officers also observed for child safety device violations. The second component involved monitoring Knoxville malls / shopping center exits for individuals transporting children under four years of age without child safety devices.

4. Young Driver Campaign. This was also a two-part campaign and was aimed at young drivers during the prom and graduation season. The campaign focused on teenage drivers and the illegal sale of alcoholic beverages to underage drivers. The first part stressed the use of radar units at locations where there had been a large number of young-driver accidents. The second part emphasized the need for establishments to "validate" alcohol beverage sales to young patrons.

5. Speeding-DWI-Seatbelt Blitz. This campaign involved an all-out effort employing several methods used previously in the program. It emphasized interstate speed enforcement and safety around the school zones. Two additional public service announcements about speeding, drunk driving, and seat belt were used in the campaign.

It is important to note that more than one of these strategies were used during a given PI\&E campaign. The strategy being emphasized by a PI\&E campaign was always employed while the campaign was underway, but other strategies were also employed during that campaign. For example, sobriety checkpoints were operated 
during the first campaign, but so were saturation patrols. Further, routine enforcement of traffic laws continued while these strategies were in effect. For example, general patrol units continued enforcing all observed violations of DWI, speeding, and non-use of seatbelts. The realities of operational law enforcement precluded the operation of only one strategy over an extended period. Availability of enforcement personnel, weather conditions, and specific enforcement needs all contributed to the Knoxville Police Department's choice of the enforcement strategies that were used during a given period.

\section{EVALUATION}

\section{Approach}

As indicated earlier in this report, the evaluation of this program was initially designed to compare various measures of effectiveness in the test site (Knoxville) with those in a similar site (Chattanooga) that operated a "nominal" enforcement program against DWI, speeding, and non-use of seatbelts. However, Chattanooga departed from its nominal program about halfway through the Knoxville program, implementing an intensive speed-enforcement campaign supported by PI\&E. This development provided the opportunity to perform a two-part evaluation of the Knoxville program.

In the first part, we examined the effectiveness of the combined enforcement program in the test site (Knoxville) relative to the nominal enforcement program in the comparison site (Chattanooga) during the first six months of the Knoxville program. To do this, we compared the first six months of data from Knoxville with the first six months of data from Chattanooga. In the second part, we estimated the effectiveness of the combined enforcement program relative to the single-violation (speeding) enforcement program operating in Chattanooga during the second six months of the Knoxville program. This was accomplished by comparing the second six months of data from Knoxville with the second six months of data from Chattanooga.

The evaluation was conducted on several levels. At the lowest level, program activity was monitored. Two types of activity were generated by this program, enforcement and PI\&E. The activity evaluation tracked and assessed the enforcement and PI\&E effort over the course of the program. The available' enforcement data consisted primarily of arrests for DWI and citations for speeding and non-use of restraints. The PI\&E data included such measures of exposure as the number of plays of PSAs by given stations, and number of special events held.

Higher levels of program evaluation dealt with the effects of the program activities on variables related to the target driving behaviors, that is, DWI, speeding, and seatbelt use. Awareness, perceived risk of enforcement, and self-reported behavior were measured through questionnaires filled out by driver's at driver license stations. The awareness component was concerned both with awareness of program messages as disseminated through PI\&E activities, and with the awareness of the enhanced 
enforcement activity generated by the program. Perceived enforcement risk dealt with the drivers' perception of the risk of getting arrested or ticketed for one of the three target violations, and self-reported behavior addressed the drivers' own reports of violating DWI, speeding, and seatbelt-use laws. The survey was conducted in Knoxville and Chattanooga in three waves, (1) shortly before the Knoxville program began, (2) about halfway through the program, and (3) shortly after the program was completed.

Unfortunately, It was not possible to compare survey results in Knoxville with those in Chattanooga during the first six months of the program. This is because the second wave of the survey was not conducted in either city until the end of March, 1991, seven months after the Knoxville program began and about a month after the Chattanooga speed enforcement program began.

A field measurement program was conducted to obtain data on actual speeding and seatbelt-use behovior. Vehicle speeds were measured and seatbelt use was observed at several locations in Knoxville and Chattanooga. Seven waves of measurements were conducted, one before and one after the Knoxville program, and five during the program.

Finally, an analysis of traffic crashes was performed for both sites. The analysis was concerned with the time variation of crashes and crash losses involving DWI, speeding, and non-use of seatbelts. Crash data were provided by the Tennessee Department of Safety.

Results

The evaluation of the Knoxville field test showed:

\section{Knoxville's combined-enforcement program}

a) was neither less effective nor more effective against any of the target violations and related crashes than was its prior enforcement program;

b) was neither less effective nor more effective against any of the target violations and related crashes than was Chattanooga's nominal-enforcement program; and

c) was less effective against speeding and related crashes than was Chattanooga's single-violation speeding program.

2. Chattanooga's single-violation speeding program

a) was more effective against speeding and related crashes (the percentage of all accidents in which there was one or more injuries decreased by about $8 \%$ after the speeding campaign began) than was its prior nominal enforcement program; and 
b) achieved its positive effects against speeding with no apparent negative effects on perceived enforcement or self-reported behavior with respect to DWI or seatbelt use. There were also no negative effects on observed use of seatbelts.

As implemented, the Knoxville program employed combined-enforcement strategies but was not accompanied by an increase in enforcement intensity (as measured by number of citations and number of officers assigned to enforce the target violation). Also, while the program did include a comprehensive PI\&E campaign, the phasing of that campaign did not coincide with the phasing of the various combined enforcement strategies.

\section{CONCLUSIONS}

Our evaluation indicated that the Knoxville program did not result in any measurable reduction in the incidence of its target unsafe driving behaviors or related crashes. The basic requirements of the combined-enforcement concept were only partially met in Knoxville. By contrast, Chattanooga's single-violation enforcement approach was effective against speeding. That program was supported by heavilyincreased enforcement intensity and by a PI\&E campaign that coincided with the enforcement effort.

Thus, Knoxville's program differed from Chattanooga's project not only in the use or non-use of combined enforcement, but also in the way in which those two enforcement approaches were executed. Therefore, it cannot be said that the reason for Knoxville's lack of success and for Chattanooga's success was that Knoxville used combined enforcement and Chattanooga used single-violation enforcement.

If the combined-enforcement approach was responsible or partly responsible for Knoxville's lack of success, then it could be because efforts targeted at multiple unsafe driving behaviors diluted Knoxville's enforcement effort and made it more difficult for the public to grasp the combined-enforcement concept. Messages aimed at several unsafe driving behaviors are inherently more complex and thus more difficult to publicize and to capture hard news coverage. Public awareness of combinedenforcement messages may have become clouded and the enforcement effort diluted in trying to maintain a high level of enforcement for three violations at once instead of just one. This might have resulted in a perception of "business as usual" by the Knoxville public.

If the lack of increased enforcement intensity played a significant role in the results of the Knoxville program, then additional support is provided for the findings of some prior research that PI\&E campaigns with enforcement themes should be backed up by a credible enforcement threat. 


\section{4 - WICHITA}

\section{SITE DESCRIPTIONS}

Wichita is located in south central Kansas and had a population of 289,000 in 1986. Population remained relatively stable in the 1980 s with about $3 \%$ growth in the 1980-1986 period projected. The current population is estimated at 300,000 . The

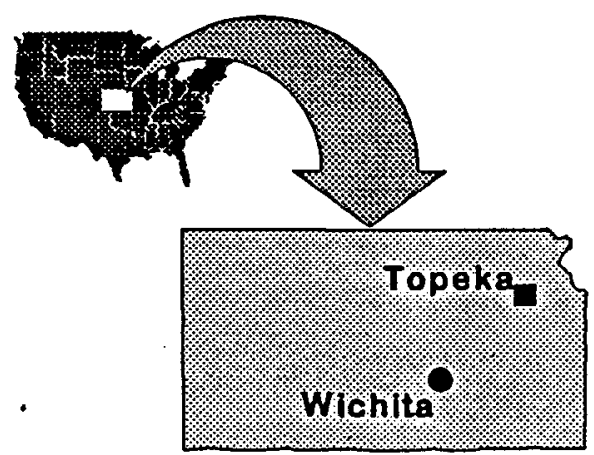
city is spread over an area of 188 square miles. Seven square miles have been added since 1982 through annexation. Aircraft manufacturing is the prominent industry. Two interstate highways pass through the city, I-235 and the Kansas Turnpike.

The major traffic law enforcement agency in the city is the Wichita Police Department (WPD), although the Kansas Highway Patrol and the Sedg-

wick county Sheriff's Department enforce traffic laws on the interstate highway segments lying within the city limits.

The WPD had 435 sworn officers and 155 civilian employees in 1989. In addition to the chief, there are three deputy chiefs, one for each of the three bureaus of the department. The bureaus are Field Services, Investigations, and Support Services. Field Services contains the two patrol divisions (called Patrol West and Patrol East) and the Special Operations Division, and has the largest staff of the three bureaus. Each division is headed by a major, and these three majors are the only majors in the department.

Traffic law enforcement is performed primarily by the Special Operations Division's Traffic Section. The Division had 43 sworn officers and 40 civilians in 1989. Officers are assigned specifically to motorcycles or radar cars: Motorcycles are used extensively, and there are currently 32 motorcycles compared to 16 radar cars being used by the Traffic Section. Motorcycle officers are assigned to cars in bad weather. Uniformed civilian personnel are responsible for accident investigation and parking enforcement. The Division also has a special DWI unit that operates Breath Alcohol Testing Vans (BAT Vans) that perform breath alcohol tests and assist in processing drivers arrested for DWI.

Wichita's comparison site was Topeka, Kansas, located in northeastern Kansas with a population of 119,000 in 1986 . This figure remained stable throughout the 1980 s. The current population of the city of Topeka is estimated at 119,883 and when combined with Shawnee County increases to 160,000 . Topeka is the capitol of Kansas which means the government is the major employer. The city covers 57 square miles. Three interstate highways pass through the city, I-70, I-470 and I-335. 
The major traffic law enforcement agency in the city is the Topeka Police Department which has 250 sworn officers and 110 civilians. The department is headed by a chief and one assistant chief. Five majors head the five divisions within the department: Traffic, Patrol, Services, Detectives and Communications. There are 40 radar cars in operation and several motorcycles. Although there is no special DWI dedicated unit or testing vans, car units are used to target DWIs.

The adult belt law in both jurisdictions requires a stop for some other violation (secondary enforcement), but violators of the child restraint law can be stopped for that violation (primary enforcement).

Again, the two sites were compared on a number of parameters and were found to be similar. These parameters included: applicable laws and ordinances, primary enforcement agency, size of geographical area, population, per capita income, unemployment, number of registered vehicles, miles of various types of roadways, historic accident patterns and trends, intensity of traffic enforcement, number of speeding citations, number of DWI arrests, historic enforcement patterns and trends, total calls for police services, and data availability.

\section{PROGRAM DESCRIPTION}

A general program theme was, chosen stressing the concept of simultaneous enforcement of DWI, speeding, and occupant restraint laws. The theme selected by the Wichita Police Department was:

Traffic Trifecta: Buckle Up - Slow Down - Driver Sober. Don't gamble with a life!

The image for the Traffic Trifecta concept was a triangle composed of three graphics, a Wichita police cruiser, breath-alcohol testing (BAT) van and motorcycle officer. Anyone stopped for speeding would automatically be observed for belt use and driving under the influence. The message was that each stop would actually be three enforcement stops in one. To give the program continuity and high recognition, a form of the theme was used on all materials and PSAs produced.

Five different combined enforcement strategies were planned for a period of approximately one year. However, the initial plans had to be modified. The city of Wichita and the Police Department experienced many unexpected problems immediately prior to and during the project period. Extensive abortion protests focused national attention on clinics in Wichita drawing police manpower and media coverage. As a result, the project kick-off scheduled for July, 1991, was delayed. As of September 3, 1991, the Wichita Police Department returned to normal operations, and so the kick-off news conference was held September 26, 1991. However, during the life of the program, the abortion protestors and supporters returned to clash on several occasions. In addition, Wichita experienced a surge in gang related activities including drive-by shootings. During these times the media chose to overlook the 
traffic safety program. The weather also drew the public's attention as several tornados touched down and Wichita suffered the largest loss of property in local history ( $\$ 570$ million in insurance claims) due to a massive hail storm on June 19 , 1992. Many police cruisers were totaled or severely damaged, again straining resources.

Unfortunately, significant police resources had to be re-allocated in the Spring of 1992, effectively putting an end to the enforcement component of the program. New PSAs were produced and enforcement levels rose again during the summer months, and the program concluded on July 31, 1992.

Despite all the distractions, most of the enforcement strategies during this 10month period were conducted with accompanying TV, radio, and newspaper coverage. Billboards were on display for the entire program, brochures were passed out to the public, television PSAs were aired and public speaking engagements were made by the police officers.

The brochure was developed to explain the Traffic Trifecta program. This brochure was also designed to hold the citations given out for violations. A total of 18,000 brochures were handed out to traffic violation offenders and the general public over the life of the Traffic Trifecta program.

In each strategy, citations were given or arrests were made as appropriate. If a stop was made for speeding or DWI, officers observed for the other violation and for seatbelt usage during the stop.

The five strategies actually conducted were:

1. Traffic Trifecta Program Introduction. The Traffic Trifecta project was introduced at a kickoff news conference where it was announced that, as part of the Traffic Trifecta Program, anyone stopped for speeding would also be checked for impaired driving and seatbelt use. Sobriety checklanes were described at the news conference as one of the enforcement strategies. A sobriety checklane using a "BAT" van was conducted as part of the kick-off, received extensive media coverage. Sobriety checklanes were continued, and saturation patrols were conducted for the remainder of this strategy. Procedures used in the checklanes and the saturation patrols were similar to those used in Knoxville.

2. "Home Safe For The Holidays." This was a holiday season strategy (Thanksgiving through New Years Eve) emphasizing safe driving. It involved an intensive PI\&E effort and saturation patrols. Media coverage, including a reporter riding in a patrol car, was prominent during this strategy 
3. Speeding / Child Passenger Safety / Seatbelts Speed enforcement activity focused on the weekly saturation patrols conducted by the dedicated DWI unit and once a month as a combined effort of the DWI unit and second detail traffic officers. In addition, Wichita police officers monitored malls and shopping center exits for individuals transporting children under fourteen years of age without child safety devices. Emphasis was placed on coupling enforcement of the adult belt law (secondary enforcement) with child restraint violations (primary enforcement).

4. Speeding / Youthful DWI Offenses. Enforcement of under age violators was conducted citywide for one month. In addition, local SADD chapters started their own safe prom campaign. The Wichita Police Department stepped up its saturation patrols during the time period when local proms were held. Regular saturation patrols continued, and officers checked for all Traffic Trifecta offenses. A sobriety checkpoint was also conducted in this phase.

5. Traffic Trifecta Concept. This final strategy replayed the general campaign used to kick-off the project with emphasis on PI\&E and hard news coverage.

Components of several strategies were repeated in other strategies. For example, checking for child restraint use actually began during the holiday season (second strategy) around shopping malls because the Wichita Police Department believes this is an important time to show enforcement. This component was repeated during National Child Passenger Safety Awareness Week in February (third strategy). Repeating several strategy components provided a feeling of continuity throughout the program and provided for the needs of the community. All three messages (buckle up, slow down, drive sober) were repeatedly mentioned and enforced.

\section{EVALUATION}

\section{Approach}

The evaluation of this program was designed to compare various measures of effectiveness in the test site (Wichita) with those in a similar site (Topeka) that operated a "nominal" or "control" enforcement program against DWI, speeding, and non-use of seatbelts.

As with the other programs, the evaluation was conducted on several levels. These levels were: 
Project activity, including enforcement and PI\&E activity.

Awareness, perceived risk of enforcement, and self-reported behavior including awareness of program messages and the enhanced enforcement activity generated by the program; drivers' perception of the risk of getting arrested or ticketed for one of the three target violations; and self-reported behavior addressing the drivers' own reports of violating DWI, speeding, and seatbelt-use laws. The survey was conducted in Wichita and Topeka in two periods, the first occurring shortly before the Wichita program began and the second shortly after the Wichita program was completed.

Measurements of vehicle speeds and observations of seatbelt-use behavior were made at several locations in Wichita and Topeka. Several waves of measurements were conducted.

Analysis of traffic accidents involving examinations of the time variation of accidents and accident losses involving DWI, speeding, and non-use of seatbelts. Accident data were provided by the Kansas Department of Transportation, Office of Traffic Safety.

Results

With respect to $D W T$, there was a significant increase in enforcement in Wichita during most of the program period. This increase was accompanied by increased PI\&E activity throughout the program period. However, there was no change in awareness of program messages related to DWI or the combined enforcement program, nor was there any change in self-reported frequency of drinking-driving. On the other hand, there was some evidence that perceived risk of DWI enforcement increased in Wichita, and several proxies of accidents involving alcohol were compatible with a program effect on DWI. These proxies declined some $20 \%$ to $35 \%$ during the Wichita program.

With respect to speeding, enforcement activity in Wichita actually decreased compared to the prior year even though there was an increase in PI\&E activity. Thus, we would not expect any positive changes in outcome, and in fact, none were found. Likewise, there were also no positive changes in Wichita with respect to outcome of the seatbelt component of the combined enforcement program, even though there were positive increases in both enforcement and PI\&E activity throughout most of the program period. Speeding and seatbelt enforcement activity in Topeka closely mirrored that in Wichita.

Thus, in Wichita, circumstances beyond the control of the program prevented a fair test of the combined enforcement concept. The speeding enforcement effort and, to some extent, the seatbelt enforcement effort, were neutralized by the transfer of resources and command emphasis to other, non-traffic enforcement activities. The 
program's effect on DWI could plausibly be attributed to the maintenance of a significant DWI enforcement threat strongly supported by PI\&E during the program period. Conceivably, increased enforcement of speeding and seatbelt violations might also have shown a positive effect had the Wichita Police Department been able to maintain the level of enforcement activity initially planned.

\section{SUMMARY AND CONCLUSIONS}

The major conclusions of the Wichita field test are:

\section{With respect to $D W I$}

- Wichita's combined-enforcement program was more effective against alcoholrelated crashes than was its prior enforcement program.

- Wichita's combined-enforcement program was more effective against alcoholrelated crashes than was Topeka's nominal enforcement program.

With respect to speeding and seatbelt use

- Wichita's combined-enforcement program was neither less effective nor more effective than was its prior enforcement program.

- Wichita's combined-enforcement program was neither less effective nor more effective than was Topeka's nominal enforcement program;

As implemented, Wichita's combined-enforcement effort against DWI involved a significant increase in enforcement intensity (as measured by number of citations and number of officers assigned to enforce the target violation), but the enforcement intensity against the other two target violations either decreased or increased only moderately. Also, while the program did include a comprehensive PI\&E campaign, the phasing of that campaign did not always coincide with the phasing of the various combined enforcement strategies. Therefore, the basic requirements of the combinedenforcement concept were only partially met in Wichita. The effort against the one target violation that did meet most of the requirements of the program (DWI) resulted in reductions in proxies of alcohol-related crashes of at least $20 \%$.

Thus, the results of the Wichita program suggest that an enforcement / PI\&E campaign that stresses more than one target violation can be effective against at least one of those violations. Whether it can also be effective against more than one violation remains to be determined, but research indicates that a crucial condition for multi-violation effectiveness is significantly increased enforcement of all of the target violations. 


\section{5 - LEXINGTON}

\section{SITE DESCRIPTIONS}

Lexington, Kentucky, is a combined urban-sural jurisdiction with a population of approximately 225,000. Lexington and Fayette County have identical boundaries and are governed by a unified governmental entity, the Lexington-Fayette Urban County

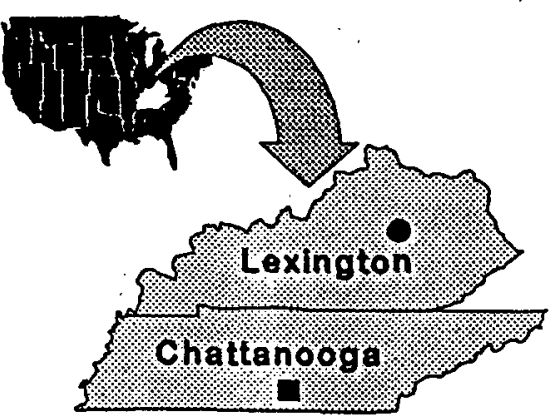

Government. The jurisdiction covers 285 square miles and has 987 miles of roads. About $35 \%$ of the population are under 25 years of age, and about $10 \%$ are 65 or older. Some $16 \%$ are classified as minority (primarily African-American). Per capita personal income for the county is about $\$ 17,000$, about the same as the state as a whole. About $10 \%$ of Lexington families were below the poverty level income in 1979 , considerably lower than the state as a whole (15\%). The unemployment rate in Lexington was 3.2\% in 1990, also much lower than that of the state as a whole which had a rate of about $5.8 \%$.

The Division of Police provides law enforcement services for the entire area which includes the urbanized city center as well as a rural area, which has numerous horse farms and two commercial horse racing tracks. IBM and the University of Kentucky are major employers. Currently, the Division of Police is authorized 370 sworn officers and has 340 officers on duty. In the past, DWI enforcement was conducted by officers on general patrol. A recent reorganization has created a Traffic Bureau with more direct traffic law enforcement responsibilities. Seatbelt usage is enforced under a county ordinance and requires a stop for some other violation (secondary enforcement).

The comparison site for Lexington was Chattanooga, Tennessee and is described in Chapter 3.

The two sites were compared on a number of parameters and were found to be similar. These parameters included: applicable laws and ordinances, primary enforcement agency, size of geographical area, population; per capita income, unemployment, number of registered vehicles, miles of various types of roadways, historic accident patterns and trends, intensity of traffic enforcement, number of speeding citations, number of DWI arrests, historic enforcement patterns and trends, total calls for police services, and data availability. 


\section{PROGRAM DESCRIPTION}

Five different combined enforcement strategies were employed sequentially during a period of approximately one year. Strategy duration ranged from one to five months. The first strategy was preceded by a period of planning and collection of baseline data, and the last strategy was followed by a one-month period of postoperations data collection. A general program theme underlaid all of the strategies, stressing the concept of simultaneous enforcement of DWI, speeding, and occupant restraint laws. The theme selected by the Lexington-Fayette Urban County Division of Police was Traffic Watch which is a program within its overall community involvement program called Safety Watch.

The logo, which appeared on the inside of the citation jacket, represents a roadway and two individuals with the words Traffic Watch underneath. This symbol appeared on all materials associated with the combined enforcement philosophy and provided identity with the overall program for each separate PI\&E piece.

The lead enforcement strategies of the five campaigns were:

1. Traffic Watch Program Introduction. This strategy continued the combined-enforcement effort begun three months earlier. The DWI component involved a special DWI enforcement squad, plus strong emphasis by general patrol units, all equipped with PBTs. Speeding enforcement strategies concentrated on high-accident locations. Seatbelt enforcement was performed in conjunction with the County's secondary enforcement ordinance with major emphasis on drivers stopped for DWI or speeding. The major PI\&E initiative associated with this strategy was a Lextran city transit bus painted on all sides with seatbelt, DWI and speeding information / enforcement messages. Lextran rotated the painted bus on all city routes throughout the program period for maximum exposure.

\section{Radar Display with Enforcement Emphasis in School Areas and} College DWI Enforcement. This strategy emphasized speed enforcement in school zones and DWI enforcement in college areas. A portable stationary radar display was positioned in local school areas to provide feedback to drivers about their speed and draw attention to school zones and return of children to school. This educational tool was supplemented by intensified speed enforcement in those areas, coupled with enforcement of the adult seat belt ordinance and child passenger safety law. DWI enforcement received special emphasis in the University of Kentucky (UK) area as well as at UK events, particularly football games. 
3. Saturation Patrol. This strategy used patrol units deployed about every two blocks in a given sector. The patrol force was rotated to other sectors on a weekly basis, so that the entire Lexington area was covered. Each patrol vehicle was equipped with radar, and the officers were trained in the use of visual cues for detecting alcoholimpaired drivers. Speeders were stopped and citations given where appropriate. Officers observed for seatbelt usage and DWI during the - stop. Another component of this strategy was a citizens reporting program for DWI offenders using cellular phones.

4. Child Restraint Enforcement and. High Incident Locations. Lexington's child restraint law is a primary enforcement law. The implementation of this strategy was timed to include National Child Passenger Safety Week and emphasized stringent enforcement of adult and child belt laws as well as concentrated enforcement at high-DWI locations and high-speeding incident locations. The use of moving radar was highlighted in this aspect of the supporting materials. PI\&E efforts included TV and radio PSA's, a news release and ride-alongs.

5. Speeding-Youthful DWT Blitz. This was a two-part strategy aimed at young drivers during the prom and graduation season. The strategy focused on teenage drivers and the illegal sale of alcoholic beverages to underage drivers. The first part stressed the use of radar units at locations where there have been a large number of young-driver accidents. The second part identified establishments for validating alcoholic beverage sales. A high-accident area analysis for individuals between 15 and 21 years of age determined the sites for radar enforcement within the city.

The formal kickoff of the program (Strategy 1) was on July 2, 1991. However, enforcement activity preceded this date by three months, increasing gradually to a roughly constant level that was attained at about the time of program kickoff. The program concluded at the end of May, 1992:

\section{EVALUATION}

\section{Approach}

This program was initially designed to compare various measures of effectiveness in the test site (Lexington) with those in a similar site (Chattanooga) that operated a "nominal" or "control" enforcement program against DWI, speeding, and non-use of seatbelts. However, during the first part of Lexington's program, Chattanooga operated an intensive speed-enforcement campaign supported by PI\&E. This 
development precluded the use of Chattanooga as a control site, but still provided the opportunity to compare the Lexington combined enforcement program with the Chattanooga single-strategy program.

In Lexington, the program period extended from April, 1991, through May, 1992. During the first three months of this period, a gradual build-up in enforcement occurred, but there was no PI\&E activity. The formal kickoff of Lexington's PI\&E campaign occurred on July 1, 1991. Chattanooga employed a "nominal" enforcement program for the three target behaviors prior to March, 1991 and operated its singlestrategy speeding program during the period beginning in March, 1991 and ending in September, 1991.

Again, the evaluation was conducted on several levels as indicated in the earlier discussion of the Knoxville and Wichita programs.

Results

In Lexington, the speed measurement data showed a drop in all measures of speeding during the program period. All of these reductions were statistically significant except the reduction in the percentage of vehicles exceeding the speed limit by at least $10 \mathrm{mph}$. In particular, there was a $12 \%$ reduction the percentage of vehicles exceeding the speed limit by at least $5 \mathrm{mph}$. In Chattanooga, there was a statistically significant drop in all measures of speeding during its single-strategy speed campaign, including the percentage of vehicles exceeding the speed limit by at least $10 \mathrm{mph}$.

The analysis of accident data in Lexington showed a significant, $17 \%$ decrease in minor injury accidents, but no decrease in surrogates of more serious injury accidents. This result is consistent with the finding that lower-speed violations decreased significantly, but higher-speed violations did not. In Chattanooga, all injury accidents decreased by about $8 \%$.

There was no measurable difference in seatbelt use in Lexington over the period of the Traffic Watch program, nor in Chattanooga over the period of the singlestrategy program. (However, Lexington started its program with relatively high beltusage rates, and was at least able to maintain these rates throughout the program period.) Since both programs were supported by heavily-increased enforcement activity and a substantial PI\&E effort against speeding, the finding of a reduction in speeding in both sites is not surprising. Lexington also increased its DWI enforcement significantly and accompanied its anti-DWI effort with increased PI\&E activity. Reductions in alcohol-related accidents of some $10 \%$ then occurred in Lexington. Multiple enforcement of speeding and DWI (looking for one violation while enforcing another) was also reported to have increased in Lexington. By contrast, Chattanooga did not mount any increased effort in DWI enforcement, and found no decrease in alcohol-related accidents.

The driver-survey data provide no support for the findings from the speed measurement data that speeding generally decreased in Lexington over the program 
period. There was no change either in awareness of speeding messages nor in selfreported speeding, and perceived enforcement of speeding actually decreased. The survey data also provided no evidence of any meaningful change in awareness, perceived enforcement, or self-reported behavior with respect to DWI, even though alcohol-related accidents decreased during the program period. A possible explanation for these inconsistencies is that the combined-enforcement concept is inherently more difficult to convey to the driving public than are single-violation messages of the type that have been used in prior enforcement-oriented programs. Then, it would be more difficult for drivers to relate the combined-enforcement messages to the specific behaviors targeted by the PI\&E campaign. Instead, the PI\&E effort in Lexington may have promoted a general awareness of highway safety issues and traffic-law enforcement which was not captured by the survey, but which, nevertheless, did support the overall combined enforcement effort.

This hypothesis is supported by the survey results from Chattanooga where a single behavior (speeding) was targeted. The Chattanooga survey data were more consistent with the reductions in observed speeding in Chattanooga during its speeding campaign. Awareness and self-reported behavior did not change, but perceived enforcement increased very significantly.

\section{SUMMARY AND CONCLUSIONS}

We conclude that Lexington's combined enforcement program was effective against both speeding and DWI. Speed measurement showed that all measures of speeding decreased, and especially those that were related to lower-speed speeding violations. The percentage of vehicles exceeding the speed limit by at least $5 \mathrm{mph}$ decreased by $12 \%$, and minor injury accidents decreased by $17 \%$. Both of these decreases were statistically significant. Minor injury accidents also decreased significantly, and this reduction seems likely to be due to the decrease in speeding, since there was no increase in seatbelt usage nor obvious changes in other factors that might influence the incidence of speeding accidents. Statistically significant reductions in alcohol-related accidents in the $10 \%$ range were also observed in Lexington.

There is also evidence that Chattanooga's speeding campaign was effective against speeding. All measures of speeding decreased during the campaign, including the percentage of vehicles exceeding the speed limit by at least $10 \mathrm{mph}(8 \%)$. Injury accidents decreased significantly also by about $8 \%$. The Chattaniooga campaign also had no apparent effect on seatbelt usage or DWI:

In some respects, the Lexington combined enforcement program had higher highway safety benefits overall than did Chattanooga's single-violation program, because the Lexington program achieved significant reductions against DWI in addition to speeding and speeding-related accidents.

Thus, this field test shows that a combined-enforcement program can be effective against at least two of its target violations, speeding and DWI. The field test suggests 
that effectiveness against a third violation, non-use of seatbelts, might also be achievable, especially in jurisdictions that have low usage rates prior to the introduction of a combined enforcement program. 


\section{6 - CONCLUSIONS}

This project provides support for the premise that a combined enforcement program against DWI, speeding, and non-use of seatbelts can have a positive general deterrence impact when properly designed and executed, but raises some questions about the practicality of operating such a program over an extended period of time. To be effective, it appears that combined enforcement programs should incorporate increased intensity of enforcement of the target laws as well as a strong public information and education (PI\&E) program supporting the enforcement effort and its highway safety benefits.

In our project, the programs that had both of these elements for either DWI or speeding or both showed an effect for those behaviors (Table 1). Programs that did not have both elements for one or both of these two behaviors did not show an effect. Our project's results for the third target behavior, nonuse of seatbelts, were inconclusive in that one site (Wichita) with increased enforcement and PI\&E showed no effect, while another site (Lexington) with increased enforcement and PI\&E was able to maintain its already high seatbelt usage rate throughout its program period. We note, however, that all of the sites had secondary-enforcement laws for adult seatbelt violations. Possibly, the combined enforcement effort would have shown more positive results against seatbelt violations had the sites been able to practice primary enforcement. (Research has shown that the largest increases in seatbelt usage have occurred in jurisdictions having primary-enforcement laws and enforcing those laws.)

Of the two sites that showed clearly positive results in this project, one (Wichita) had an effect on DWI, and the other (Lexington) had an effect on DWI and speeding. Wichita experienced a reduction of at least $20 \%$ in proxies of alcohol-related crashes. Lexington had a reduction of alcohol-crash proxies in the $10 \%$ range and also a $12 \%$ reduction in the number of vehicles exceeding the speed limit by at least $5 \mathrm{mph}$. Further, Lexington also had a reduction in minor injury accidents of about $17 \%$, a possible reflection of these lower speeds.

One of the two comparison sites selected for this study (Chattanooga) decided to operate a speeding campaign during a portion of the period in which it was being used as a comparison site. The campaign was accompanied by an intensive PI\&E effort, but did not involve increased enforcement of DWI or nonuse of seatbelts. This campaign also achieved a positive general deterrence impact on speeding-related accidents: injury accidents in Chattanooga declined some $8 \%$ during its program. When compared to Lexington (which also had a successful effort against speeding), Chattanooga apparently had a greater effect on speeding-related accidents, since it showed a reduction in all injury accidents, not just minor injury accidents. However, this effect was achieved without the positive effect on DWI (and the possible positive effect on nonuse of seatbelts) that occurred in Lexington. Thus, there is some evidence to suggest that a combined enforcement program might have a greater 
overall highway safety impact than a single-violation program of comparable magnitude. However, this evidence is certainly not conclusive and needs to be supported by further research to verify.

With respect to the operation of a combined enforcement program, we found that such a program can place ä strain on police resources because of the need to simultaneously increase enforcement intensity for all three of the target behaviors. In times of high demand for polices services and lack of adequate resources to meet that demand, it may be difficult for some departments to allocate sufficient additional resources to traffic-law enforcement.

It is possible that a more effective PI\&E program would help lessen the amount of additional enforcement intensity needed for a combined enforcement effort. For example, we noted in our discussion of the results of the Lexington program how a PI\&E program explicitly emphasizing the combined enforcement concept might be difficult for drivers to grasp. It could be that the PI\&E effort would be more productive if the individual targeted behaviors were emphasized sequentially in the PI\&E campaign, with the combined-enforcement message assuming a secondary role.

In sum, the results of this study are encouraging but inconclusive as to the traffic safety impact of combined enforcement of DWI, speeding, seatbelt usage laws. In two of the test sites it was not possible to consistently maintain increased enforcement activity and associated publicity for all three of the target behaviors. The one site that was able to maintain increased enforcement activity and a high level of publicity for all three behaviors produced positive results against DWI and speeding. This site did not produce any increase in seatbelt usage, but was able to maintain its already high usage rate. Another site that was able maintain increased publicity and related publicity against just one of the target behaviors, DWI, showed positive results for that target behavior, but for none of the others. The study also indicated that the single-emphasis approach employing increased enforcement and PI\&E also can have an impact which may be greater for the targeted behavior than that of the combined approach. 
Table 1: Summary of Program Activity and Outcome

\begin{tabular}{|c|c|c|c|c|}
\hline \multirow{2}{*}{$\begin{array}{l}\text { Target } \\
\text { Behavior }\end{array}$} & \multirow{2}{*}{ Item } & \multicolumn{3}{|c|}{ Site } \\
\hline & & $\begin{array}{c}\text { Knoxville } \\
\ldots .\end{array}$ & Wichita & Lexington \\
\hline DWI & $\begin{array}{l}\text { Activity } \\
\text { Enforcement Intensity } \\
\text { PI\&E } \\
\text { Outcome } \\
\text { Accidents }\end{array}$ & $\begin{array}{c}\text { No increase } \\
\text { Increase } \\
\text { No change }\end{array}$ & $\begin{array}{l}\text { Increase } \\
\text { Increase } \\
\text { Decrease }\end{array}$ & $\begin{array}{l}\text { Increase } \\
\text { Increase } \\
\text { Decrease }\end{array}$ \\
\hline Speeding & $\begin{array}{l}\text { Activity } \\
\text { Enforcement Level } \\
\text { PI\&E } \\
\text { Outcome } \\
\text { Measured Speeding } \\
\text { Accidents }\end{array}$ & $\begin{array}{l}\text { No change } \\
\text { Increase } \\
\text { No change } \\
\text { No change }\end{array}$ & $\begin{array}{l}\text { Decrease } \\
\text { Increase } \\
\text { No change } \\
\text { No change }\end{array}$ & $\begin{array}{l}\text { Increase } \\
\text { Increase } \\
\text { Decrease } \\
\text { Decrease }\end{array}$ \\
\hline Seatbelt Use & $\begin{array}{l}\text { Activity } \\
\text { Enforcement Level } \\
\text { PI\&E } \\
\text { Outcome } \\
\text { Measured Use } \\
\text { Accidents }\end{array}$ & $\begin{array}{l}\text { No change } \\
\text { Increase } \\
\text { No change } \\
\text { No change }\end{array}$ & $\begin{array}{l}\text { Increase } \\
\text { Increase } \\
\text { No change } \\
\text { No change }\end{array}$ & $\begin{array}{l}\text { Increase } \\
\text { Increase } \\
\text { No change* } \\
\text { No change }\end{array}$ \\
\hline
\end{tabular}

* Usage rate was high at the beginning of the program 